\title{
Selected Macroeconomic Variables and Stock Market Movements: Empirical evidence from Thailand
}

\author{
Joseph Ato Forson', Jakkaphong Janrattanagul ${ }^{2}$
}

\begin{abstract}
This paper investigates and analyzes the long-run equilibrium relationship between the Thai stock Exchange Index (SETI) and selected macroeconomic variables using monthly time series data that cover a 20-year period from January 1990 to December 2009. The following macroeconomic variables are included in our analysis: money supply (MS), the consumer price index (CPI), interest rate (IR) and the industrial production index (IP) (as a proxy for GDP). Our findings prove that the SET Index and the selected macroeconomic variables are cointegrated at I (1) and have a significant equilibrium relationship over the long run. Money supply demonstrates a strong positive relationship with the SET Index over the long run, whereas the industrial production index and consumer price index show negative long-run relationships with the SET Index. Furthermore, in non-equilibrium situations, the error correction mechanism suggests that the consumer price index, industrial production index and money supply each contribute in some way to restore equilibrium. In addition, using Toda and Yamamoto's augmented Granger causality test, we identify a bi-causal relationship between industrial production and money supply and unilateral causal relationships between CPI and IR, IP and CPI, MS and CPI, and IP and SETI, indicating that all of these variables are sensitive to Thai stock market movements. The policy implications of these findings are also discussed.
\end{abstract}

KEY WORDS: $\quad$ macroeconomic variables; cointegration; Thai Stock Exchange index (SETI); T-Y augmented Granger-causality

JEL Classification: $\mathrm{CO} 1 ; \mathrm{C} 12 ; \mathrm{C} 22 ; \mathrm{C} 58$

${ }^{1}$ Graduate School of Public Administration, National Institute of Development Administration (NIDA), Thailand

${ }^{2}$ Wang Yanan Institute for Studies in Economics, Xiamen University, China

\section{Introduction}

The relationships between macroeconomic variables and stock market movements have been the focus of financial and economic literature for many years. In

Correspondence concerning this article should be addressed to: Joseph Ato Forson, Graduate School of Public Administration, National Institute of Development Administration (NIDA) 118 M003, Seri Thai Road, Klong Chan, Bangkapi, Bangkok 10240 Thailand, Tel: +66-840-724-426 Email: datoeagle@yahoo.com general, stock markets facilitate economic growth by enhancing liquidity and providing funds for industrialization and economic development. They also act as interesting investment centers. Stock price movements are by their nature essentially random, and prices adjust rapidly in response to economic news, such as news regarding domestic and international shocks. Daily gains and losses by stock market investors demonstrate the extent to which individual stock returns fluctuate in response to a variety of unanticipated events. Essentially, stock prices are determined by sup- 
ply and demand. A high demand for a particular stock will drive the stock price up. Conversely, a loss of confidence in a particular stock will cause an outflow of capital as investors sell the stock; the low demand for that particular stock will be reflected in a lower price. In sum, the stock market moves up or down based on many factors, and there is no method that can accurately predict the exact movements of stock market. The factors that influence the stock market can be divided into two broad categories: systematic risk and unsystematic risk. As stated above, the relationships between macroeconomic variables and stock market movements have been studied extensively, especially in advanced and emerging economies. Ross (1976) introduced the Arbitrage Pricing Theory (APT), which states that multiple risk factors can be used to explain the returns on a financial asset. Although the APT was initially accepted, it was criticized for failing to specify the exact factors that should be used to explain financial returns. Later, Chen, Roll and Ross (1986) further analyzed the APT and linked a linear function of various macroeconomic factors to the returns on financial assets. The seminal contributions of Chen et al., (1986) to the APT literature provided a framework for further analysis of the relationship between stock market movements and macroeconomic variables. As a result, many empirical studies are based on the APT model.

Because most macroeconomic variables are nonstationary, the use of regression analysis with the OLS technique tends to produce misleading results. To address this issue, Granger (1986) and Johansen (1991) developed tools based on the concept of cointegration that could be used to analyze long-run equilibrium relationships. Cointegration tests have since been widely used to analyze the relationship between macroeconomic variables and stock market movements. The significance of the cointegration approach is premised on the fact that it allows non-stationary data to be examined in the context of a long-term relationship and permits an assessment of whether the variables are cointegrated of the same order (for example, at I(1)). In addition, with adjustments for error-correction, this method allows an examination of the short-term adjustments that occur as variables move toward their long-run equilibriums.

The concepts described above have been applied in numerous empirical studies that document the relationship between stock market movements and macroeconomic variables. However, most research in this area has focused on stock markets in the United States (Chen et al., 1986; Flannery, 2002; Narayan \& Narayan, 2012) and other developed countries, such as Japan (Mukherjee \& Naka, 1995), Poland (Okon, 2012), China (Zhao, 1999) and Singapore (Maysami \& Koh, 2000). Although some studies have analyzed the relationships between macroeconomic variables and stock market movements in developing countries, including Pakistan (Nishat \& Shaheen, 2004), the United Arab Emirate (Al-Tamimi, Alwan, \& Abdel Rahman, 2011), Turkey (Çagli, Halac, Taskin, 2010; Eraslan, 2013) and Malaysia (Rahman, Mohd Sidek \& Tafri, 2009), little research has been conducted in Southeast Asia and in Thailand in particular (See Kwanchanok, 2000; Liangnakthongdee, 1991; Seehalak, 2004; Tri, 2005). The motivation for the present paper arose after a review of the existing literature regarding the relationship between selected macroeconomic variables and stock market movement. Although the model relationship has been well established in other countries, only limited research has been conducted in Thailand, and only a few of the Thai studies have appeared in English. As in most countries, macroeconomic indicators play a significant role in driving the stock market in Thailand; therefore, further research regarding policies that may affect macroeconomic variables in Thailand is warranted. The main purpose of this paper is to identify and explain the relationship between selected macroeconomic variables and the movement of the Thai stock market (SET Index). It is our desire to contribute to the existing literature by supplementing and updating previously published evidence relating to the relationship between macroeconomic data and the Thai stock market. The study period comprises 240 consecutive months from January 1990 to December 2009. Because we are dealing with a time series analysis, we use a cointegration approach to examine the relationship between the selected macroeconomic variables and the movement of the SET Index toward the long-run equilibrium.

Liangnakthongdee (1991) studied the relationships between Thailand stock market indices (SET Index) and certain macroeconomic variables using the APT 

sures of inflation, announcements of increases in these variables tend to depress the stock market. Similarly, because increases in the money supply lead to inflation and thus cause interest rates to increase, announcements of increases in the money supply also tend to decrease stock prices.

Nishat and Shaheen studied the long-run equilibrium relationship between selected macroeconomic variables and the Pakistani (Karachi) Stock Exchange Index and found two long-term equilibrium relationships among these variables. Specifically, their results indicated that industrial production is the largest positive determinant of stock prices in Pakistan and that inflation is the largest negative determinant (Nishat \& Shaheen, 2004). However, reverse causality was observed in the relationship between industrial production and stock prices. Al-Sharkas (2004) utilized the vector error correction model (VECM) to determine the impact of selected macroeconomic variables (i.e., money supply, the interest rate and inflation) on the Amman Stock Exchange (ASE). The empirical results showed that stock prices and the selected macroeconomic variables have a long-term equilibrium relationship, and that money supply and the industrial production index each has a positive relationship with stock prices, whereas the consumer price index has a negative relationship with stock prices. Eraslan (2013) recently used the Fama and French three-factor asset pricing model to investigate variations in excess portfolio returns on the Istanbul Stock Exchange. Market risk factor, size risk factor and book-tomarket ratio risk factor were used as the explanatory variables. He concluded that although the Fama and French three-factor model has some power to explain variations in excess portfolio return on the Istanbul Stock Exchange, this power is not strong throughout the test period. Narayan and Narayan (2012) investigated whether U.S. macroeconomic conditions (specifically, the exchange rate and the short-term interest rate) have effects on seven selected Asian stock markets-namely, China, India, the Philippines, Malaysia, Singapore, Thailand, and South Korea-using daily data for the period 2000-2010. They divided the sample into a pre-crisis period (pre-August 2007) and a crisis period (post-August 2007). They found that in the short run, the interest rate has a statistically insignificant effect on returns in all countries, except for the Philippines during the crisis period, and that depreciation has a statistically significant and negative effect on returns in all countries except China (regardless of the crisis). With respect to long-term relationships among the variables, although the authors found cointegration in the pre-crisis period for five of the seven countries (India, Malaysia, the Philippines, Singapore, and Thailand), they found no such relationship during the crisis period, implying that the financial crisis has actually weakened the link between stock prices and economic fundamentals. Okon (2012) investigated investors' reactions to mandatory offers of shares on the Warsaw stock market using the capital asset pricing model. That study sought to offer guidance to potential investors and to lay the groundwork for further research.

\section{The Economy of Thailand in Perspective}

Thailand is located in the heart of Southeast Asia and has a total population of approximately 67 million people. Bangkok is the capital city and the "Thai Baht" is the national currency (1 Thai Baht is approximately equal to 0.032916 U.S. dollars). Thailand is considered to be a promising developing country and is currently the second largest economy in Southeast Asia after Indonesia. Thailand experienced rapid economic growth between 1985 and 1995 (before the Asian financial crisis in 1997). Its current economy is relatively stable and has an average annual growth rate of $8 \%$. Thailand specializes in the production of electronic components and automobile parts, and its heavy exporting sectors contribute significantly to the economy. According to the International Monetary Fund (IMF), Thailand's estimated nominal GDP (PPP) in 2010 was approximately $\$ 584.768$ billion; two-thirds of the estimated Thai GDP was derived from exports. The estimated GDP per capita in 2010 was $\$ 8,643$, making it the fourth richest nation in Southeast Asia (after Singapore, Brunei and Malaysia) in terms of GDP per capita. Thailand mainly exports agricultural products, and rice is the country's most important cash crop. Thailand is considered a leading global exporter of rice.

\subsection{Stock Exchange of Thailand (SET)}

The Stock Exchange of Thailand (SET) is the national secondary market and is located in Bangkok. The SET 


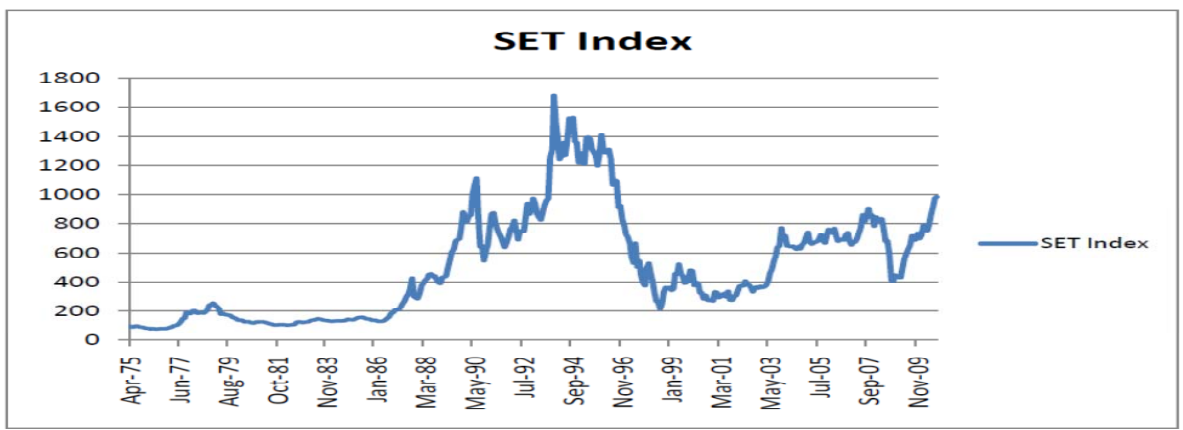

Figure 1. Thailand SET Index Monthly Movement, 1975-2010

started trading on April 30, 1975 and currently lists 653 companies. The indices of the Thai stock exchange are the SET Index, SET50 Index and SET100 Index. The SET Index is the main public market index and is a market capitalization-weighted price index comprising all stocks traded on the Thai stock market (the SET50 Index and SET100 Index comprise the top 50 stocks and top 100 stocks, respectively, ranked by market capitalization). In general, the SET Index is heavily influenced by the energy sector. The SET is not as large or as liquid as stock markets in developed countries. Between late 2009 and the beginning of 2011, the SET index increased from approximately 500 points to more than 1,000 points. On February 28, 2011, the SET Index closed at 987.91 points and had a total market capitalization of $8,003,836.37$ million Baht. The daily average trading turnover was 2,982.02 million shares, representing a market value of approximately 27,953.02 million Baht.

Changes in macroeconomic data have affected the movement of the SET index in one manner or another for the past 30 years. Figure 1 shows SET index movements from April 1975 to December 2010. When the Stock Exchange of Thailand (SET) started trading in April 1975, the market hovered between 100 and 200 points due to the high savings interest rate (the annual savings interest rate was more than $10 \%$ during this period). In 1986, the Bank of Thailand started to reduce the savings interest rate on a yearly basis to stimulate private consumption and investment. At the same time, Thailand liberalized its financial policies to encourage foreign direct investment. As a result, the SET index increased from approximately 200 points in 1986 to 1,100 points by $1989-1990$. The SET index continued to climb steadily through 1993 1994, reaching a peak of almost 1,700 points, but dropped to 200 points during the 1996-1998 periods due to the floating Thai Baht (i.e., the Asian Financial Crisis). Between 2003 and 2007, the SET index increased from 400 points to more than 800 points, but this gain was short-lived; in 2008, the SET index began a sharp decline due to the sub-prime mortgage crisis in the United States and once again reached a low of 200 points. In 2009, as the US crisis began to resolve and investor confidence was restored, the SET index began to rise again and managed to exceed 1,000 points in 2011 despite the unfavorable political situation in Thailand at that time.

\section{Research Methodology, Hypotheses and Model Specifications}

\subsection{Research Hypotheses}

Industrial Production Index (IP): GDP is normally used to represent the overall aggregate output of an economy; however, due to the infrequency of available GDP data (Thai GDP data are usually available on a quarterly and yearly basis), we decided to use the Industrial Production Index, which is available monthly, as a proxy for GDP in this paper. Moreover, a significant relationship appears to exist between GDP and 
Table 1. Data Summary Statistics (at level specification)

\begin{tabular}{cccccc}
\hline & SETI & CPI & IP & IR & MS \\
\hline Mean & 709.39580 & 80.29625 & 109.24070 & 3.31563 & 553006.60000 \\
Median & 678.98500 & 82.95000 & 93.65000 & 2.00000 & 473569.00000 \\
Maximum & 1682.85000 & 109.50000 & 214.87000 & 10.00000 & 1174551.00000 \\
Minimum & 214.53000 & 52.00000 & 49.06000 & 0.75000 & 181953.00000 \\
Std. Deviation & 323.06930 & 15.66226 & 44.42925 & 2.74807 & 274562.60000 \\
Skewness & 0.75850 & -0.11000 & 0.63683 & 0.72835 & 0.42224 \\
Kurtosis & 2.96309 & 1.94288 & 2.08207 & 2.41080 & 1.89696 \\
Jarque-Bera & 23.02626 & 11.62385 & 24.64788 & 24.69162 & 19.29861 \\
Probability & 0.00001 & 0.00299 & 0.00000 & 0.00000 & 0.00006 \\
\hline Observation & 240 & 240 & 240 & 240 & 240 \\
\hline
\end{tabular}

Industrial Production Index (Chen et al., 1986; Fama, 1981; Humpe \& Macmillan, 2009; Nishat \& Shaheen, 2004). Therefore, we hypothesize that an increase in the industrial production index is likely to lead to economic expansion in Thailand, which in turn will increase the expected future cash flows of firms listed on the Stock Exchange of Thailand (SET).

Consumer Price Index (CPI): CPI is used to represent price level increases. Previous evidence indicates that the CPI has a negative relationship with stock market movements (Al-Sharkas, 2004; Fama, 1981; Mukherjee \& Naka, 1995; Nishat \& Shaheen, 2004; Zhao, 1999). Accordingly, we hypothesize that increases in CPI will negatively influence Thai stock market movements.

Money Supply (MS): The narrow money supply (M1) is discussed in this paper. The relationship between money supply and stock market movement has yielded mixed results in previous studies. For example, Fama (1981); Flannery and Protopapadakis (2002) each observed that an increase in money supply ultimately increases inflation, which in turn depresses the stock market. However, Maysami and Koh (2000); Mukherjee and Naka (1995) and certain studies of the Thai stock market Kwanchanok (2000); Liangnakthongdee (1991) have identified positive relationships between money supply and stock market movement. Mukherjee and Naka (1995) argued that an increase in the monetary supply acts as an economic stimulus, re- sulting in increased cash flows (the corporate earnings effect) and higher stock prices. We investigate whether this theory holds for the Thai stock market index and hypothesize that there is positive relationship between money supply and SETI movements.

Interest Rate (IR): Also called the cost of capital, IR can be classified into two types: the savings interest rate and the borrowing interest rate. Most studies that have evaluated the interaction between interest rates and stock market movements (Kwanchanok, 2000; Liangnakthongdee, 1991; Mukherjee \& Naka, 1995; Narayan \& Narayan, 2012) have found negative relationships between interest rates and stock prices. One proffered explanation is that an increase in the interest rate affects the discount rate, which ultimately decreases the value of a stock. A related explanation is that an increase in the interest rate makes alternative investment opportunities more attractive. Specifically, as the interest rate rises, investors tend to invest less in stock and more in other investment assets, causing stock prices to fall.

\subsection{Data Description}

Because of the limited availability of data, the sample period comprises 240 monthly observations of each variable from January 1990 to December 2009. The secondary data used in this study were obtained from various sources, including the SET SMART publica- 


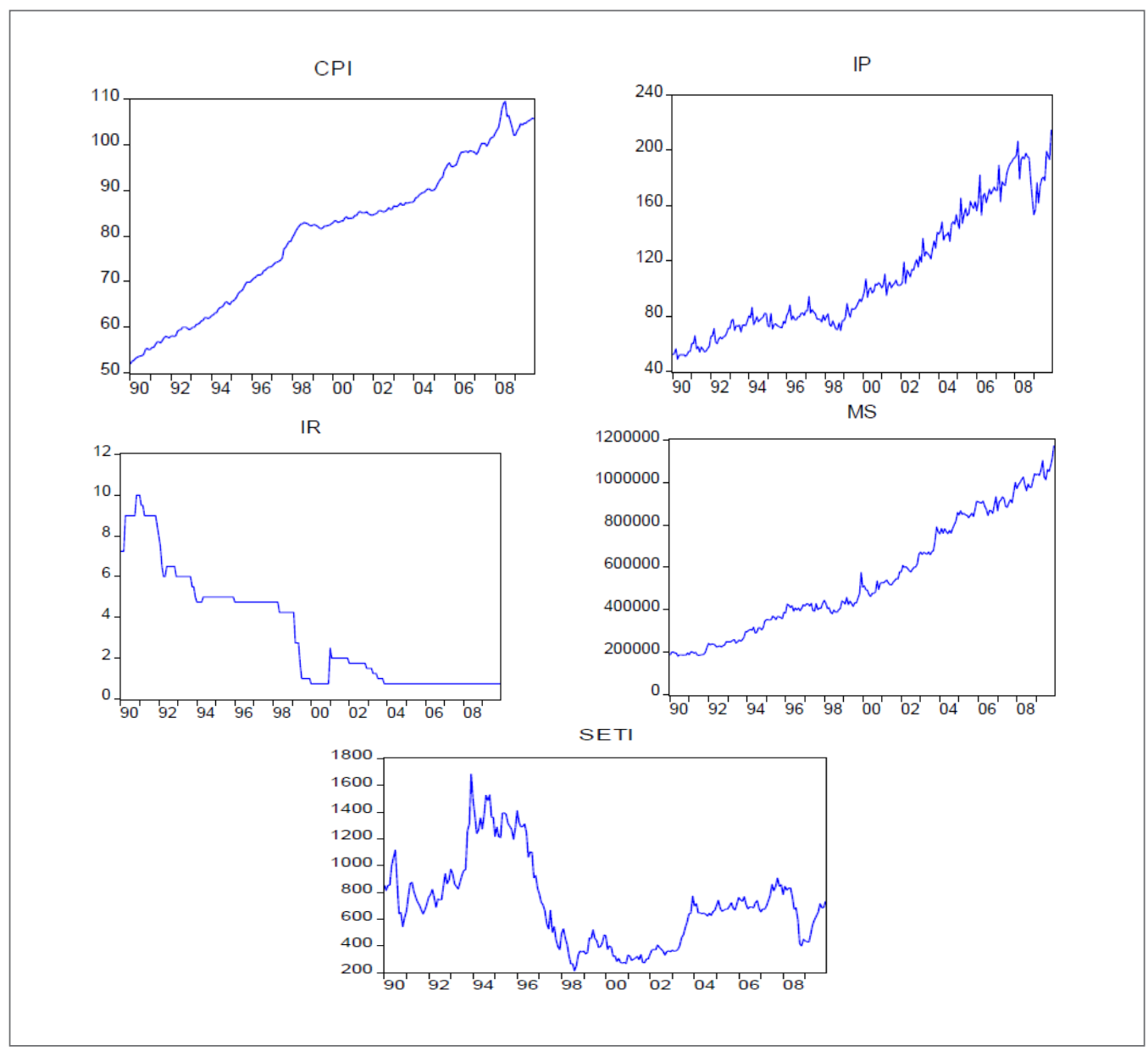

Figure 2. Graphical illustration of the variables (at level)

tion of the Stock Exchange of Thailand (SET). Macroeconomic data for Thailand were obtained from publications of the Bank of Thailand (BOT). These data were used to determine the stock market movement in Thailand taking into account the impacts of selected macroeconomic variables.

Table 1 provides the descriptive summary statistics (at level specification), which were generated with E-views statistical software. The Stock Exchange of Thailand Index (SETI) has a mean of 709.3958 and a standard deviation of 323.0693. The index of industrial production has a mean of 109.2407 and a standard deviation of 44.42925. CPI has a mean and standard deviation of 80.29625 and 15.66226 , respectively.
Interest rate has a mean of $3.315625 \%$ and a standard deviation of $2.748072 \%$. Money supply has a mean and standard deviation of 553006.6 million baht and 274562.6 million baht, respectively.

Because a visual plot of the data is usually the first step in the analysis of any time series, Figure 2 presents the graph of each variable. The graphs in Figure 2 show that all selected variables are non-stationary, which means that their respective means and variances are not constant. For example, the graphs of variables CPI, IP, and MS show fluctuating increasing curves with some decreases during the 2007-2008 downturn caused by the US sub-prime financial crisis. In contrast, the graph of the variable IR shows a trend 


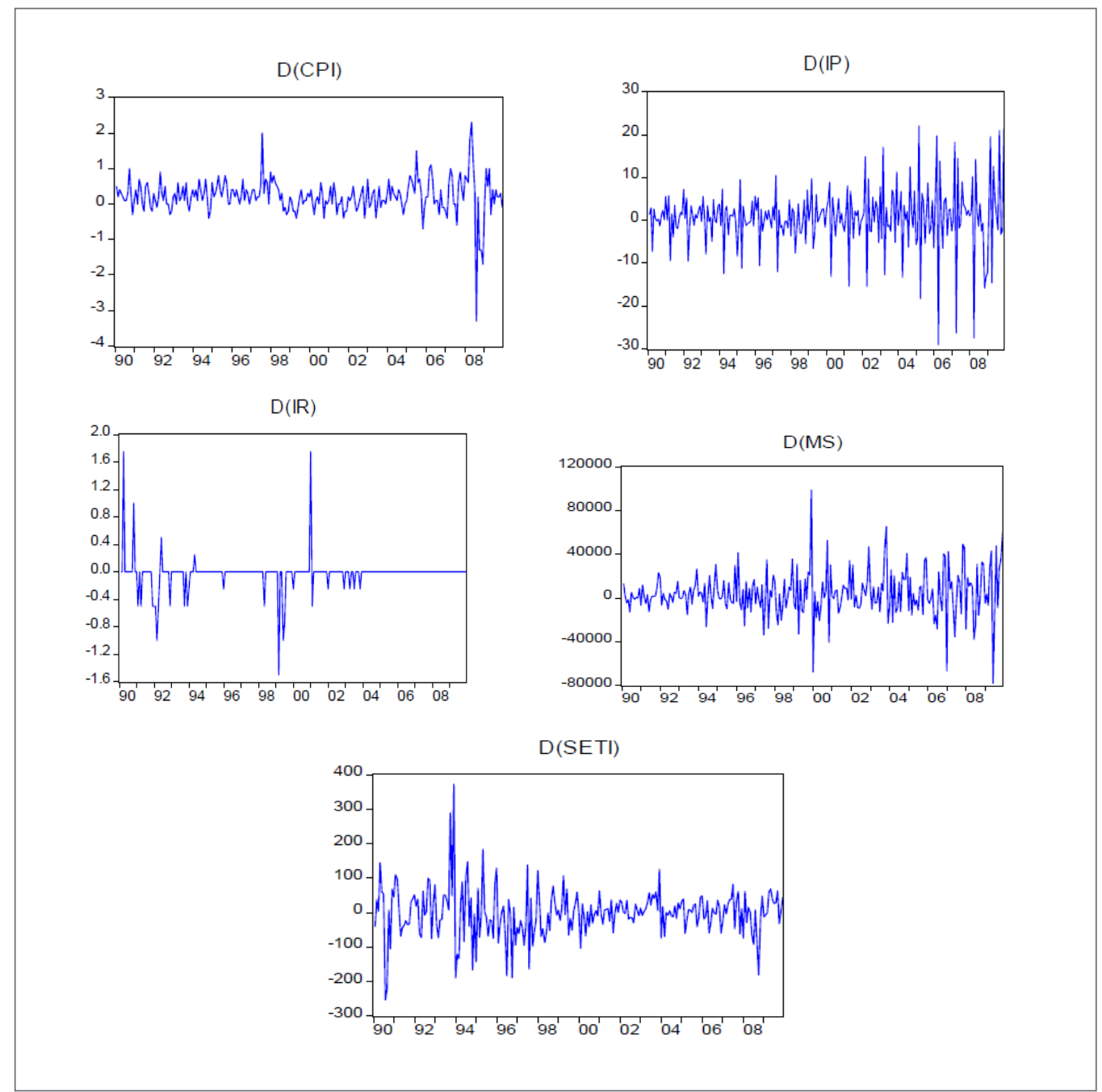

Figure 3. Graphical illustrations of the variables (at first difference)

that starts to decrease in 1990 and then remains stable. SETI shows very volatile movements with two significant drops; the former was due to the floating Thai Baht in 1997, when the Asian financial crisis began, and the latter was due to the 2008 sub-prime crisis in the United States.

As shown in figure 3, when the first order difference is taken, the variables have no trending behavior; this suggests that the variables are stationary at the first difference.

\subsection{Model Specification}

Graphical analysis is only a preliminary step in time series modeling. When conducting a time series analysis, the concepts of stationarity and unit root are extremely important. If these concepts are ignored in the analysis of non-stationary time series, spurious regression problems will occur. Accordingly, using the EViews program and following Johansen's (1991) methodology, we test for cointegration and apply the error correction model (ECM); the cointegration approach 
allows us to assess changes in the long-run equilibrium relationships between selected Thai macroeconomic variables and SET movements. To test for cointegration, we first must determine whether each variable is integrated of the same order. To do this, we use the augmented Dickey-Fuller test (Dickey, 1988) to test for unit root. The ADF test is estimated in three different forms, each of which is based on a different hypothesis (Gujarati, 2003). Specifically:

$\mathrm{Y}_{\mathrm{t}}$ is a Random Walk and assumes the following form:

$\Delta Y_{t}=\delta Y_{t-1}+\alpha_{i} \sum_{i=1}^{m} \Delta Y_{t-1}+\varepsilon_{i}$

$\mathrm{Y}_{\mathrm{t}}$ is a Random Walk with an intercept:

$\Delta Y_{t}=\beta_{1}+\delta Y_{t-1}+\alpha_{i} \sum_{i=1}^{m} \Delta Y_{t-1}+\varepsilon_{i}$

$\mathrm{Y}_{\mathrm{t}}$ is a Random Walk with an intercept and time trend:

$\Delta Y_{t}=\beta_{1}+\beta_{2 t}+\delta Y_{t-1}+\alpha_{i} \sum_{i=1}^{m} \Delta Y_{t-1}+\varepsilon_{i}(3)$

The Phillips-Perron (PP) test is another method used to detect the unit root (Phillips \& Perron, 1988). The intuitions behind the PP test are the same as for the ADF test; however, the PP test uses a non-parametric statistical method to handle serial correlation in the error term and does not add the lagged difference into the model. The PP model is described as follows:

$\mathrm{Y}_{\mathrm{t}}$ is a Random Walk and assumes the following form:

$\Delta Y_{t}=\delta Y_{t-1}+\varepsilon_{i}$

$\mathrm{Y}_{\mathrm{t}}$ is a Random Walk with an intercept:

$\Delta Y_{t}=\beta_{1}+\delta Y_{t-1}+\varepsilon_{i}$

$\mathrm{Y}_{\mathrm{t}}$ is a Random Walk with an intercept and time trend:

$\Delta Y_{t}=\beta_{1}+\beta_{2 t}+\delta Y_{t-1}+\varepsilon_{i}$

In each case, the null hypothesis is that $\delta=0$; that is, there is a unit root, and the time series is non-stationary. The alternative hypothesis is that $\delta<0$; that is, the time series is stationary. If the null hypothesis is rejected, it means that $\mathrm{Yt}$ is a stationary time series at I (0). If not, we have to take the difference until the null hypothesis is rejected. In this paper, the unit root test will be detected in levels and first differences, and we assume that each variable will have a unit root at level; this requires us to take first difference order to have stationary data. If each variable is integrated of the same order of first difference at I (1), it implies that we can test for long-run equilibrium relationships using Johansen's (1991) cointegration method and that there will be at least one cointegration among these variables. The cointegration method is linked to the vector error correction model (VECM). The VECM is similar to the VAR model, but unlike the VAR model, the VECM can be used when all endogenous variables are nonstationary and cointegrated. In addition, the VECM permits us to account for short-term adjustments that occur on the path toward the long-run equilibrium. Specifically, assuming that a given variable Yt is out of equilibrium and that its value is above (below) its equilibrium value, it will start falling (rising) to correct the equilibrium error in the next period. The vector error correction model (VECM) is described below:

$\Delta Y_{t}=\mu+\sum_{j=1}^{k-1} \Gamma_{j} \Delta Y_{t-j}+\alpha \beta^{\prime} Y_{t-k}+\varepsilon_{t}$

Where

- $\Delta$ denotes the first difference order, for example, $\Delta Y_{t}=\left(Y_{t}-Y_{t-1}\right)$

- The term $Y_{t}$ represents the selected macroeconomic variables (SETI, MS, IR CPI, and IP) that will be tested in this model, and each variable is a $\mathrm{p} \mathrm{x} 1$ vector integrated of the same order.

- $\mu$ is a $\mathrm{p} \times 1$ vector of constant.

- The mechanism $\sum_{j-1}^{k-1} \tau \Delta Y t-1$ comprises the vector autoregressive components where the $\mathrm{p} x \mathrm{p}$ matrix denotes the coefficients of variables' shortrun adjustments toward long-term equilibrium.

- The equation $\alpha \beta^{\prime} Y_{t-k}$ describes the long-term equilibrium relationship (stationary linear combination of $\beta^{\prime} Y$ ) where $\alpha$ stands for $\mathrm{p} x \mathrm{r}$ speed of adjustment coefficient, $\beta$ ' denotes the cointegration vector with $\mathrm{Y}_{\mathrm{t}}$ integrated of the same order, and $\mathrm{k}$ denotes the lag structure.

- $\varepsilon_{t}$ is the vector white-noise error term. 
Determining the exact order of cointegration among the variables might not be sufficient to establish the causal relationship between the set of macroeconomic variables and the Thai stock index. Therefore, the Granger causality test must be performed. The Granger causality test is the most common way to test the causal relationship between two variables and involves estimating a simple vector autoregression (VAR) equation, as shown below:

$X_{t}=\sum_{i=1}^{n} \alpha_{i} Y_{t-1}+\sum_{j=1}^{n} \beta_{j} X_{t-1}+\mu_{1 t}$

$Y_{t}=\sum_{i=1}^{m} \lambda_{i} Y_{t-1}+\sum_{j=1}^{m} \delta_{j} X_{t-1}+\mu_{2 t}$

where it is assumed that the disturbances $\mu_{1 \mathrm{t}}$ and $\mu_{2 \mathrm{t}}$ are uncorrelated. Both equations [8.1] and [8.2] represent that variable $\mathrm{X}$ is decided by lagged variable $\mathrm{Y}$ and $\mathrm{X}$ except that the dependent variables are interchanged in each case. Granger causality means that the lagged $\mathrm{Y}$ significantly influences $\mathrm{X}$ in equation [8.1] and viceversa in equation [8.2]; thus, researchers can jointly test if the estimated lagged coefficients $\sum \alpha_{i}$ and $\sum \lambda_{t}$ are different from zero with F-statistics. However, the traditional Granger causality test has many limitations. First, a two-variable Granger causality test that does not consider the effects of other variables may be subject to specification bias. Specifically, because causality tests are sensitive to model specifications and to the number of lags, evidence of a two-variable causality is fragile (Gujarati, 2003). In addition, time series data are often non-stationary, which could exacerbate the spurious regression problem. In addition, when the variables are integrated, the F-test procedure is not valid because the test statistics do not have a standard distribution.

To overcome these shortcomings, an alternative test was developed by Toda and Yamamoto (1995). This test may be used irrespective of whether $Y_{t}$ and $X_{t}$ are I (0), I (1) or I (2) and whether they are noncointegrated or cointegrated of an arbitrary order. This method is widely known as the Toda and Yamamoto (1995) augmented Granger causality test and is based on the following equations;

$Y_{t}=\alpha+\sum_{i=1}^{k+d} \beta_{i} Y_{t-1}+\sum_{j=1}^{k+d} \gamma_{j} X_{t-j}+\mu_{y t}$
$Y_{t}=\alpha+\sum_{i=1}^{k+d} \theta_{i} Y_{t-1}+\sum_{j=1}^{k+d} \delta_{j} Y_{t-j}+\mu_{x t}$

where $d$ is the maximal order of integration order of the variables in the system, $h$ and $k$ are the optimal lag length of $\mathrm{Y}_{\mathrm{t}}$ and $\mathrm{X}_{\mathrm{t}}$, and are error terms that are assumed to be white noise with zero mean, constant variance and no autocorrelation. All that we are required to do is to determine the maximal order of integration $\mathrm{d}$, which we expect to occur in the model, and to construct a VAR in their levels with a total of $(k+d)$ lags.

\section{Empirical Results and Analysis}

We begin by modifying the VECM models. For example, by identifying the data generating process (DGP), we can identify each variable's characteristic. To proceed further, we first need to determine whether our model will include the components of an intercept and time trend. Later, the set of selected time series macroeconomic variables (SETI, MS, IR CPI, and IP) is used to detect unit root. Only sets of variables that are integrated of the same order will be subject to further analysis on cointegration. Next, we must choose the statistical tool to select the lag length order. Commonly used tools to select the lag length order are the Akaike information criterion (AIC) and Schwarz information criterion (SIC). For the sake of simplicity, we will use these two approaches in our study. The number of order cointegration relationships will be determined using the trace statistic and maximum eigenvalue statistic. Once the number of cointegration relationships has been established, the next step is to compute the long-term equilibrium relationship and error correction by regressing $\Delta \mathrm{Y}_{t}$ against the lag difference of $\Delta \mathrm{Y}_{\mathrm{t}}$ and $\mathrm{Y}_{\mathrm{t}-\mathrm{k}}$ where $\mathrm{Y}_{\mathrm{t}}$ represents the selected macroeconomic variables (SETI, MS, IR CPI, and IP).

\subsection{Unit Root Tests}

When time series data become stationary, we call this integrated degree 0 or I (0) but when we take first, second, or third differences to make a time series stationary, we call this I (1), I (2), or I (3), respectively. The augmented Dickey-Fuller test (ADF) and the PhillipsPerron (PP) test are employed to determine the presence of unit root for the model in this paper. The unit root tests are estimated for both an intercept with time trend and an intercept only. The t-statistics and p-val- 
Table 2. Results of Unit Root Test (Level Specifications)

\begin{tabular}{lllllllll}
\hline & \multicolumn{1}{l}{ ADF } & \multicolumn{2}{c}{ PP } & \multicolumn{2}{c}{ ADF } & \multicolumn{2}{c}{ PP } \\
\hline \multirow{2}{*}{ At Level } & \multicolumn{2}{c}{ Intercept } & \multicolumn{2}{c}{ Intercept } & \multicolumn{2}{c}{ Intercept and Trend } & \multicolumn{2}{c}{ Intercept and Trend } \\
\cline { 2 - 9 } SETI & t-stats & $p$-value & Adj.t-stat & $p$-value & t-statistics & $p$-value & Adj.t-stat & $p$-value \\
CPI & -1.664 & 0.4484 & -1.816 & 0.3721 & -1.538 & 0.8142 & -1.714 & 0.7425 \\
IP & -0.766 & 0.8264 & -0.821 & 0.8109 & -2.384 & 0.3870 & -2.222 & 0.4748 \\
IR & 0.705 & 0.9921 & 0.639 & 0.9905 & -1.752 & 0.7245 & -2.929 & 0.1552 \\
MS & -1.128 & 0.7051 & -1.183 & 0.6822 & -1.443 & 0.8460 & -1.825 & 0.6897 \\
\hline
\end{tabular}

Table 3. Results of Unit Root Test (First Difference)

\begin{tabular}{lccccccccc}
\hline & \multicolumn{2}{c}{ ADF } & \multicolumn{2}{c}{ PP } & \multicolumn{2}{c}{ ADF } & \multicolumn{2}{c}{ PP } \\
\hline \multirow{2}{*}{ First Difference } & \multicolumn{2}{c}{ Intercept } & \multicolumn{2}{c}{ Intercept } & \multicolumn{2}{c}{ Intercept and Trend } & \multicolumn{2}{c}{ Intercept and Trend } \\
\cline { 2 - 10 } SETI & t-stats & $p$-value & Adj.t-stat & $p$-value & t-stats & $p$-value & Adj.t-stat & $p$-value \\
CPI & -15.01 & $0.000^{* *}$ & -15.005 & $0.000^{* *}$ & -14.998 & $0.000^{* *}$ & -14.992 & $0.000^{* *}$ \\
IP & -10.92 & $0.000^{* *}$ & -10.9456 & $0.000^{* *}$ & -10.904 & $0.000^{* *}$ & -10.935 & $0.000^{* *}$ \\
IR & -11.87 & $0.000^{* *}$ & -253.736 & $0.001^{* *}$ & -11.867 & $0.000^{* *}$ & -367.630 & $0.001^{* *}$ \\
MS & -14.09 & $0.000^{* *}$ & -14.2082 & $0.000^{* *}$ & -14.080 & $0.000^{* *}$ & -14.188 & $0.000^{* *}$ \\
\hline
\end{tabular}

Note: ** Denotes significance at the $5 \%$ level where SETI = Stock Exchange of Thailand Index, CPI = Consumer Price Index, IP $=$ Industrial Production Index, $I R=3$ months savings interest rate, and MS = Money Supply

Table 4. Results of the Appropriate Lag length

\begin{tabular}{ccccccc}
\hline Lag & Log L & LR & FPE & AIC & SIC & HQ \\
\hline 0 & -6587.945 & NA & $9.00 \mathrm{E}+18$ & 57.83285 & 57.90806 & 57.86319 \\
1 & -4746.808 & 3585.373 & $1.08 \mathrm{E}+12$ & 41.90182 & $42.35305^{*}$ & 42.08388 \\
2 & -4698.579 & 91.80259 & $8.85 \mathrm{E}+11$ & 41.69807 & 42.52532 & $42.03184^{*}$ \\
3 & -4673.687 & 46.29055 & $8.87 \mathrm{E}+11$ & 41.69901 & 42.90229 & 42.1845 \\
4 & -4642.524 & 56.58585 & $8.41 \mathrm{E}+11$ & 41.64495 & 43.22425 & 42.28215 \\
5 & -4630.555 & 21.20761 & $9.45 \mathrm{E}+11$ & 41.75926 & 43.71459 & 42.54817 \\
6 & -4605.27 & 43.69519 & $9.46 \mathrm{E}+11$ & 41.75675 & 44.08811 & 42.69738 \\
7 & -4582.931 & 37.62286 & $9.73 \mathrm{E}+11$ & 41.7801 & 44.48748 & 42.87244 \\
8 & -4548.554 & 56.39017 & $9.02 \mathrm{E}+11$ & 41.69785 & 44.78125 & 42.94191 \\
9 & -4525.867 & 36.22097 & $9.28 \mathrm{E}+11$ & 41.71813 & 45.17756 & 43.1139 \\
10 & -4494.611 & 48.52858 & $8.88 \mathrm{E}+11$ & 41.66325 & 45.49871 & 43.21074 \\
11 & -4469.479 & 37.91759 & $8.98 \mathrm{E}+11$ & 41.6621 & 45.87358 & 43.3613 \\
12 & -4430.748 & $56.73869^{*}$ & $8.09 \mathrm{e}+11^{*}$ & $41.54165^{*}$ & 46.12915 & 43.39256 \\
\hline
\end{tabular}

Note: * indicates lag order selected by the criterion presented in the table (each test at $5 \%$ level). LR: sequential modified LR test statistic, FPE: final prediction error, AIC: Akaike information criterion, SIC: Schwarz information criterion, HQ: Hannan-Quinn information criteria 
ues of the unit root test results are displayed at level in Table 2, below:

Null Hypothesis: $\delta=0$ (each variable has a unit root). Alternative Hypothesis: $\delta<0$ (each variable does not have a unit root).

The values in Table 3 represent the t-statistics and $\mathrm{p}$-values at first difference. The results of the ADF and PP tests suggest that at the first difference, we are able to reject the unit root null hypothesis at the $5 \%$ significance level; therefore, we conclude that all five selected macroeconomic variables have a unit root at level. This requires us to take the first difference order to achieve stationary data for an intercept and an intercept with time trend. Additionally, the identification of the data generating process (DGP) suggests that an intercept without time trend must be included in the tested equation. With all five macroeconomic variables now integrated of the same order at I (1), we proceed to consider whether they have long-run equilibrium relationships.

\subsubsection{Appropriate Lag Length Selection}

There are many methods of selecting the lag length in statistics. The most commonly used methods are the Akaike information criterion (AIC) and Schwarz information criterion (SIC). We use these methods to select the appropriate lag length for our model. Table 4 indicates that LR, FPE, and AIC show significant results at 12 lag length periods. This is considered very long, and it would be extremely complicated to apply this many lag length periods to the model equation. Due to time and space constraints, we opted to keep our model simple and straightforward. Therefore, the lag length for these five macroeconomic variables will be selected based on the SIC (Schwarz information criterion), which indicates a lag length of 1 period.

\subsubsection{Cointegration Test for Long-run Equilibrium Relationships}

Because the empirical analysis in this paper is subject to a linear relationship, it does not matter whether the variables have a time trend. This is because there is only one cointegration relationship among the variables (see more details below).

Table 5 shows the results of the trace statistic and max-eigenvalue tests. The trace statistic, 89.08741 , is greater than the critical value, 77.81884 . This means that we can reject the null hypothesis that $r=0$ and accept the alternate hypothesis that $r>0$. The same is true for the max-eigenvalue test: the max-eigenvalue statistic, 61.73567, is larger than the critical value, 39.37013; thus, we reject the null hypothesis that $r$ $=0$ and accept that $\mathrm{r}=1$ at a $1 \%$ significance level. In sum, both tests (trace and max-eigenvalue) show that there is only one cointegration relationship.

\subsection{Cointegration Results}

The cointegration test was conducted for Thai stock market movements and the four selected macroeconomic variables. Only partial results are shown in this section. Table 6 presents the significant outcomes of the long term cointegration relationships with Thai stock market movements.

The cointegration test was normalized based on SETI. The estimates of the long term cointegration vectors and corresponding t-statistics are displayed in Table 6. The results show that there are three significant long-term relationships among this group of variables. Specifically, we can reject the null hypothesis and accept the alternative hypothesis for money supply, inflation rate, and the industrial production index (IP), which implies that these three variables form a cointegration relationship with Thai stock market movements. However, the result for the interest rate is insignificant, which indicates that the interest rate (IR) does not have a cointegration relationship with the Thai stock market index and that the null hypothesis cannot be rejected.

The estimated coefficient of money supply is positive and statistically significant at a 99\% level of confidence. The value and sign of the money supply coefficient implies that if there is an increase of 1 million Thai baht in the money supply, the Thai stock index (SETI) will increase by 0.0204 index points in the long run. The estimated coefficient of CPI is negative, as expected, and statistically significant at a $90 \%$ level of confidence. The value and sign of the CPI coefficient implies that if there is an increase of 1 index point in the CPI, there will be a decrease of 56.6921 index points in the Thai stock index (SETI) in the long run. The industrial production index (IP) is statistically significant at a $99 \%$ level of confidence. However, the estimated coefficient of IP is not as expected and is not consistent with the assumption set forth in the research hypothesis. 
Table 5. The Number of Cointegration Vectors

$\begin{array}{ll}\text { Sample (Thailand): } & \text { 1990M01 2009M12 } \\ \text { Included observations: } & 239 \text { after adjustments } \\ \text { Trend assumption: } & \text { Linear deterministic trend } \\ \text { Series: } & \text { SETIMS IR IP CPI } \\ \text { Lags interval: } & 1 \text { to } 1\end{array}$

\section{Unrestricted Cointegration Rank Test (Trace)}

\begin{tabular}{cccccc}
\hline Ho & HA & Eigenvalue & Trace Statistic & 0.01 Critical Value & $p$-value \\
\hline $\mathbf{r}=\mathbf{0}$ & $r>0$ & 0.227643 & $89.08741^{*}$ & 77.81884 & $0.0007^{*}$ \\
$\mathbf{r} \leq \mathbf{1}$ & $r>1$ & 0.061895 & 27.35174 & 54.6815 & 0.8406 \\
$\mathbf{r} \leq \mathbf{2}$ & $r>2$ & 0.032825 & 12.08118 & 35.45817 & 0.929 \\
$\mathbf{r} \leq \mathbf{3}$ & $r>3$ & 0.015868 & 4.104415 & 19.93711 & 0.8949 \\
$\mathbf{r} \leq \mathbf{4}$ & $r>4$ & 0.001177 & 0.281524 & 6.634897 & 0.5957 \\
\hline
\end{tabular}

\begin{tabular}{cccccc}
\hline \multicolumn{6}{l}{ Unrestricted Cointegration Rank Test (Maximum Eigenvalue) } \\
\hline Ho & HA & Eigenvalue & Trace Statistic & 0.01 Critical Value & p-value \\
\hline $\mathbf{r}=\mathbf{0}$ & $r=1$ & 0.227643 & $61.73567^{*}$ & 39.37013 & $0.0000^{*}$ \\
$\mathbf{r}=\mathbf{1}$ & $r=2$ & 0.061895 & 15.27056 & 32.71527 & 0.7265 \\
$\mathbf{r}=\mathbf{2}$ & $r=3$ & 0.032825 & 7.976765 & 25.86121 & 0.9051 \\
$\mathbf{r}=\mathbf{3}$ & $r=4$ & 0.015868 & 3.822891 & 18.52001 & 0.8776 \\
$\mathbf{r}=\mathbf{4}$ & $r=5$ & 0.001177 & 0.281524 & 6.634897 & 0.5957 \\
\hline
\end{tabular}

Notes: *Denotes rejections of the null hypothesis at the 0.01 level. P-values and $r$ stand for the number of co-integrating vectors.

Table 6. Cointegration Results

\begin{tabular}{ccc}
\hline Cointegration Equation & CointEq1 & Statistical Results \\
\hline SETI(-1) & 1 & \\
MS(-1) & $0.0204(7.55990)$ & Positive significant at $99 \%$ \\
IR(-1) & $30.27(0.29011)$ & Not Significant \\
CPI(-1) & $-56.6921(1.74709)$ & Negative significant at $90 \%$ \\
IP(-1) & $-104.2606(-8.31897)$ & Negative Significant at $99 \%$ \\
\hline
\end{tabular}

Note: There are three significant long-term relationships among this group of variables.

\subsubsection{Long-term Cointegration Analysis}

The empirical results in table 6 show that the Thai stock market index (SETI) and the three selected macroeconomic variables-namely, money supply, consumer price index and the industrial production index-are cointegrated and have a long-term equilibrium relationship. Figure 4 (below) depicts the cointegration relationship. The horizontal line repre- sents monthly data from January 1990 to December 2010, and the vertical line is the value of the cointegration. The graph denotes the long term relationship between SETI and the macroeconomic variables. This long-term relationship fluctuates and the movement is very volatile, especially during the financial crisis and economic downturn. The long-run relationship between SETI movements and money supply is found 


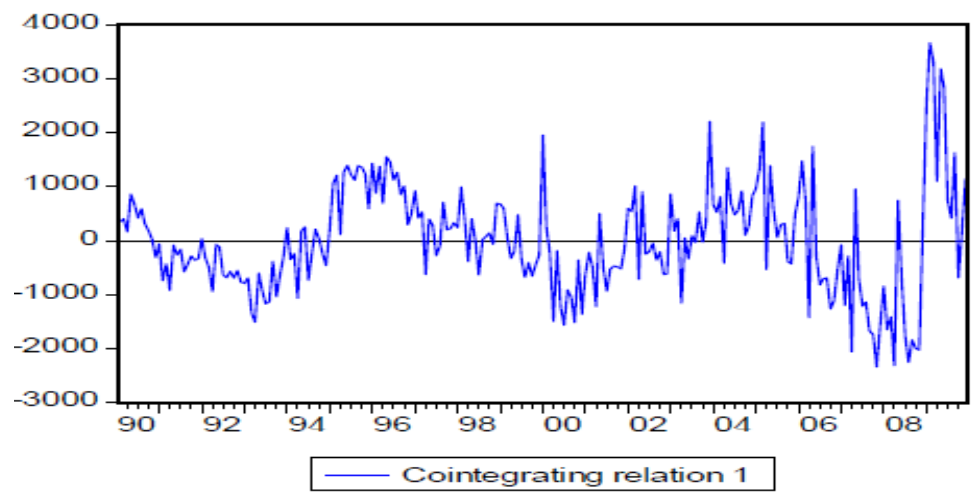

Figure 4. The Long-term movements between the Thai Stock Index (SETI) and the Selected Macroeconomic Variables

Table 7. Adjustments to Error Correction with standard errors and t-values

\begin{tabular}{clllll}
\hline Co-Integrating Equation & D(SETI) & D(MS) & $\mathbf{D}(\mathrm{IR})$ & $\mathbf{D}(\mathrm{IP})$ & $\mathrm{D}(\mathrm{CPI})$ \\
\hline Adjustment Coefficient & 0.00022 & $-4.156834^{*}$ & $5.23 \mathrm{E}-06$ & $0.002912^{*}$ & $9.18 \mathrm{E}-05^{*}$ \\
Standard Error & 0.00465 & 1.34923 & $1.70 \mathrm{E}-05$ & 0.00043 & $3.20 \mathrm{E}-05$ \\
t- values & $(0.04738)$ & -3.0809 & $(0.31337)$ & $(6.75884)$ & $(2.85458)$ \\
\hline
\end{tabular}

Note: * Denotes significance at the $1 \%$ level

to be positive. This finding is consistent with previous studies (Al-Sharkas, 2004; Kwanchanok 2000; Liangnakthongdee, 1991; Maysami \& Koh, 2000; Mukherjee \& Naka, 1995). An increase in the supply of money in the Thai economy might explain this positive finding.

The inflation rate (denoted as CPI) shows a negative influence on the movements of the Thai stock market. This finding is consistent with previous studies (Al-Sharkas, 2004; Fama, 1981; Liangnakthongdee, 1991; Mukherjee \& Naka, 1995; Nishat \& Shaheen, 2004; Zhao, 1999) and confirms the negative long-run relationship between the inflation rate and the SET Index. The reason for the negative relationship is that an increase in the inflation rate will increase the discount rate; this will reduce the expected future cash flows of listed companies and ultimately cause lower stock prices.

The level of real economic output in Thailand, which is measured in this study by IP (Industrial Pro- duction Index), is found to be significant in the long run. Although most studies have found a positive relationship between economic output and stock market prices, our results indicate a negative long-term relationship between IP and the Thai stock market. It is difficult to explain the inconsistent result, but one possible reason is that the Thai industrial production index is already adjusted for higher price levels caused by inflation. Accordingly, IP may not be a good indicator of aggregate economic activities in Thailand.

According to the Granger representation theorem, when variables are cointegrated, there must be an error correction (EC) that describes the short-run adjustments of co-integrated variables as they move toward their long-term equilibrium values. Table 7 describes the error corrections for this study, as well as the standard errors and t-values. The findings are statistically significant at the $1 \%$ significance level and suggest that money supply, the industrial production 
Table 8. T-Y Granger Causality Test

\begin{tabular}{|c|c|c|c|c|}
\hline Dependent variable & \multicolumn{2}{|c|}{ Direction of Causality df } & \multirow{2}{*}{$\begin{array}{l}\text { Chi-sq. } \\
31.91231^{* *}\end{array}$} & \multirow{2}{*}{$\begin{array}{l}\text { Prob. } \\
0.0000\end{array}$} \\
\hline \multirow{5}{*}{$\mathbb{I P}$} & $M S>I P$ & 1 & & \\
\hline & $\mathbb{R}>\mathbb{P}$ & 1 & 0.247278 & 0.6190 \\
\hline & $C P|>| P$ & 1 & 0.007963 & 0.9289 \\
\hline & SETI & 1 & 3.423426 & 0.0643 \\
\hline & All & 4 & 47.39695 & 0.0000 \\
\hline \multirow{5}{*}{ MS } & $\mathrm{IP}>\mathrm{MS}$ & 1 & $8.509335^{*}$ & 0.0035 \\
\hline & $\mathrm{IR}>\mathrm{MS}$ & 1 & 0.180429 & 0.6710 \\
\hline & $\mathrm{CPI}>\mathrm{MS}$ & 1 & 0.90751 & 0.3408 \\
\hline & SETI>MS & 1 & 0.016721 & 0.8971 \\
\hline & ALL & 4 & 10.49396 & 0.0329 \\
\hline \multirow{5}{*}{$\mathbb{R}$} & $|P>| R$ & 1 & 0.034723 & 0.8522 \\
\hline & $M S>\mathbb{R}$ & 1 & 1.027334 & 0.3108 \\
\hline & $C P I>\mid R$ & 1 & $4.863128^{*}$ & 0.0274 \\
\hline & SETI>IR & 1 & 0.404678 & 0.5247 \\
\hline & All & 4 & 5.313913 & 0.2566 \\
\hline \multirow{5}{*}{ CPI } & $|\mathrm{P}>\mathrm{CP}|$ & 1 & $4.499767^{*}$ & 0.0339 \\
\hline & $M S>C P I$ & 1 & $8.864683^{*}$ & 0.0029 \\
\hline & $|\mathrm{R}>\mathrm{CP}|$ & 1 & 0.080989 & 0.776 \\
\hline & SETI $>C P I$ & 1 & 1.868943 & 0.1716 \\
\hline & ALL & 4 & 13.9619 & 0.0074 \\
\hline \multirow{5}{*}{ SETI } & IP>SET| & 1 & 0.08033 & 0.7768 \\
\hline & $M S>S E T I$ & 1 & 1.585239 & 0.2080 \\
\hline & $|\mathrm{R}>\mathrm{SET}|$ & 1 & 0.475227 & 0.4906 \\
\hline & CPI>SETI & 1 & $5.766161^{*}$ & 0.0163 \\
\hline & All & 4 & 6.432001 & 0.1691 \\
\hline
\end{tabular}

Note: Denotes ${ }^{*} p<0.05,{ }^{* *} p<0.01$ levels

index and the CPI are responsible for the error correction adjustment process when the variables are out of equilibrium.

The adjusted coefficient of money supply is negative. This means that when the movement of money supply deviates from its long-term equilibrium value in the short run, i.e., money supply is too high to be in equi- librium, it will begin falling in the following month by 4.156834 index points to restore its equilibrium. Conversely, the respective adjustment coefficients of the industrial production index and consumer price index are positive. This means that, when they are too low to be in equilibrium, they will start increasing in the following month to correct the equilibrium error. 


\subsubsection{Toda- Yamamoto Augmented Granger- Causality}

Having determined the maximum order of integration using the ADF and PP tests, with the same integrating order I (1), and the optimal lag length of one (1) (based on SIC), we set the following null and alternative hypotheses based on equations [8.3] and [8.4]:

\section{$\mathbf{H}_{0}: \sum_{j=1}^{k} \gamma_{j}=0$ or $X_{t}$ does not cause $Y_{t}$ \\ $H_{0}: \sum_{j=1}^{k^{\prime}} \delta_{j}=0$ or $Y_{t}$ does not cause $X_{t}$ \\ $\mathrm{H}_{1}: \sum_{j=1}^{k} \gamma_{j} \neq 0$ or $X_{t}$ causes $Y_{t}$ \\ $\mathrm{H}_{1}: \sum_{\mathrm{j}=1}^{\mathrm{k}_{1}^{\prime}} \delta_{\mathrm{j}} \neq 0$ or $\mathrm{Y}_{\mathrm{t}}$ causes $\mathrm{X}_{\mathrm{t}}$}

We calculated the F-statistics for the modified Wald test. Table 8 above presents the test results. Based on the estimated coefficients and values of the chi-square test, money supply Granger causes industrial production with a bi-direction when the dependent variables are changed with a high level of significance $(\mathrm{p}<0.05)$. This is in line with our priori expectations and has substantial theoretical soundness. Specifically, when the supply of money increases, it triggers demand; as producers compete to meet this demand, industrial production is increased in both the short and long runs. In a similar manner, IP Granger causes MS through the payment of expenditures, such as factory wages, which increases the liquidity in the system. As a result, MS increases simultaneously with IP. CPI Granger causes IR. An increase in the rate of inflation as measured by the CPI poses a major risk to lending institutions; to offset this risk, a corresponding risk premium is charged in the form of higher interest rates. IP Granger causes CPI. An increase in IP implies corresponding increases in employment opportunities and employee incentives. As a result, the demand for goods and services will increase, which may increase the supply of money, which in turn translates into a higher rate of inflation. MS Granger causes CPI. An increase in the supply of money translates into higher rate of inflation as measured by the CPI. Additionally, CPI Granger causes SETI. An increase/decrease in CPI may cause the Thai stock index to increase/decrease as well. These results are consistent with Mukherjee \& Naka, 1995; Narayan \& Narayan, 2012 and Tri, 2005.

\subsection{Policy Suggestions}

This paper establishes that, in the long run, the stock market and certain macroeconomic variables (namely, money supply, consumer price index and industrial production index) work in the same cointegration system. Difficulties may arise if we are missing one of these variables. In fact, macroeconomic variables and the stock market support each other; hence, they are cointegrated.

A good and resilient economy depends on mechanisms that drive the growth of the stock market because the stock market determines people's wealth. The profits generated by the stock market encourage people to consume more; as people consume more, economic outputs and the money in circulation in the economy increase; these factors have the propensity to expand the economy. However, the fear of inflation arises when an economy develops too fast. The expectation of increased inflation is one of the factors that depress the stock market. Moreover, excess money supply is not the only cause of higher inflation rates; anything that increases the cost of production leads to higher price levels. Accordingly, policy makers must pay more attention to increases in international oil prices, especially in the case of Thailand. Thailand is an importer of oil, and every time the price of oil increases, it trickles down to higher production costs. This subsequently causes commodity prices to increase, which translates into higher inflation rates. Higher inflation rates depress both the Thai economy and the Thai stock market.

To overcome the challenges of inflation, the Bank of Thailand should develop a monetary policy that seeks to increase the interest rate and thereby reduce the quantity of money in circulation. However, policy targets that produce changes in macroeconomic variables may unintentionally cause the economy to slow down. For example, controlling the money supply through the interest rate channel may depress the stock market. Policy decision-makers must have a good understanding of the potential consequences of any policies that are formulated.

The year 2011 was a challenging year for investors in the stock market due to the negative effects of several shocks to the global stock market. For example, natural disasters like the flooding in Thailand and the tsunami in Japan had significant negative impacts on 
the stock markets of the affected countries and ultimately led to negative effects on the global stock market. Policy makers should develop contingency plans to ameliorate the effect of such disasters in the future.

\section{Conclusion and Recommendations}

In conclusion, this paper makes a significant contribution to the existing financial and economic literature, and we are optimistic that later generations will benefit from reading this study and using it as an investment guide, either in Thailand or elsewhere. This paper examined the long-term equilibrium between the SET index and selected macroeconomic variables during the past 20 years using monthly data for the narrow money supply (M1), industrial production index, interest rate, and consumer price index. Many statistical tools and techniques were used to evaluate the relevant relationships, including the detection of unit root, Johansen's cointegration concept, and the vector error correction model.

The empirical findings suggest that only one cointegration relationship exists. Specifically, this set of selected macroeconomic variables and the Thai stock index are co-integrated at I (1). In addition, three significant long-term relationships exist among the variables: MS, CPI and IP have positive and negative longterm relationships with Thai stock market movements respectively. Interestingly, our results for the industrial production index do not support the postulates presented by Chen et al., 1986; Eraslan, 2013; Fama, 1981; Humpe \& Macmillan, 2009; Nishat \& Shaheen, 2004. This might be because the industrial production index in Thailand is adjusted, which may not be the case elsewhere. However, previous findings on CPI were confirmed by the existence of a negative relationship between CPI and Thai stock market movements (See Al-Sharkas, 2004; Fama, 1981; Mukherjee \& Naka, 1995; Nishat \& Shaheen, 2004; Zhao, 1999). We also found a positive relationship between money supply and the Thai stock market, which confirms earlier postulates (See Eraslan, 2013; Kwanchanok, 2000; Liangnakthongdee, 1991; Maysami \& Koh, 2000; Mukherjee \& Naka, 1995).

The directions of causality were also established in this paper using Toda and Yamamoto's (1995) augmented Granger causality test. We found a bi-directional causal relationship between IP and MS and uni- lateral directional relationships between CPI and IR, IP and CPI, MS and CPI, and CPI and SETI. Future research could use entirely different variables by incorporating natural disasters such as the 2011 flooding. This is an area that warrants further research.

Macroeconomic variables that were not included in this study that would be interesting to examine include foreign direct investment (FDI), the major global stock indices (such as the Dow Jones index), foreign inflows/ outflows, export/import volumes and political stability. In addition, many policies have been launched to stimulate and reinforce SET liquidity. Future research should evaluate the effects of the structural changes that result from such policies.

\section{References}

Al-Sharkas, A. A. (2004). Dynamic Relations Between Macroeconomic Factors and Jordanian Stock Market. International Journal of Applied Econometrics and Quantitative Studies, 1 (1), 97-114

Al-Tamimi, H. H., Alwan, A. A., \& Abdel Rahman, A. A. (2011). Factors Affecting Stock Prices in the UAE Financial Markets. Journal of Transnational Management, 16 (1), 3-19.

Çagli, E. C., Halac, U., \& Taskin, D. (2010). Testing Long-run Relationships between Stock Market and Macroeconomics Variables in the Presence of Structural Breaks: The Turkish Case. International Research Journal of Finance and Economics, 48, 49-60.

Chen, N. F., Roll, R., \& Ross, S. A. (1986). Economic forces and the stock market. Journal of Business, 59 (3), 383-403.

Dickey, D.A., \& Fuller, W. A. (1979). Distribution of the Estimators for Autoregressive Time Series with a Unit Root. Journal of the American Statistical Association, 74 (366), 427-431.

Eraslan, V. (2013). Fama and French Three-Factor Model : Evidence from Istanbul Stock Exchange. Business and Economics Research Journal, 4 (2), $11-22$.

Fama, E. F. (1981). Stock returns, real activity, inflation and money. American Economic Review, 71 (4), 545-565.

Flannery, M. J., \& Protopapadakis, A. A. (2002). Macroeconomic Factors Do Influence Aggregate Stock 
Returns. The Review of Financial Studies, 15 (3), 751-782.

Granger, C. W. J. (1986). Developments in the Study of Co-integrated Economic Variables. Oxford Bulletin of Economics and Statistics, 48 (3), 213-228.

Gujarati, N. D. (2003). Basic econometrics (4th ed.). Boston, MA: McGraw-Hill/Irwin.

Humpe, A., \& Macmillan, P. (2009). Can Macroeconomic Variables explain long term stock market movements? A Comparison of the US and Japan. Applied Financial Economics, 19 (2), 111-119.

Johansen, S. (1991). Estimation and Hypothesis Testing of Co-integration Vectors in Gaussian Vector Autoregressive Models. Econometrica, 59 (6), 1551-1580.

Kwanchanok, T. (2000). The relationship between SET Indices and the Macroeconomic Indicators (Unpublished master's thesis). Chiang Mai University, Chiang Mai, Thailand.

Liangnakthongdee, V. (1991). The relationship between SET Indices and the Macroeconomic Indicators (Unpublished master's thesis). National Institute of Development Administration (NIDA), Bangkok, Thailand.

Maysami, R.C., \& Koh, T. S. (2000). A vector error correction model for the Singapore stock market. International Review of Economics and Finance, 9 (1), 79-96.

Maysami, R. C., Howe, L. C., \& Hamzah, M. A. (2004). Relationship between Macroeconomic Variables and Stock Market Indices: Cointegration Evidence from Stock Exchange of Singapore's All-S Sector Indices. Journal Pengurusan, 24, 47-77.

Mukherjee, T. K., \& Naka, A. (1995). Dynamic relations between macroeconomic variables and the Japanese stock market: An application of a vector error correction model. Journal of Financial Research, 18 (2), 223-237.

Narayan, S., \& Narayan, P. K. (2012). Do US macroeconomic conditions affect Asian stock markets? Journal of Asian Economics, (23), 669-679.

Nishat, M., \& Shaheen, R. (2004). Macroeconomic Factors and Pakistani Equity Market. The Pakistan Development Review, 43 (4), 619-637.

Okon, S. (2012). Investor Reaction to Mandatory Offers on the Warsaw Stock Exchange. Contemporary Economics, 6 (2), 74-83.
Phillips, P. C. B., \& Perron, P. (1988). Testing for a Unit Root in Time Series Regression. Biometrika, 75 (2), 335-346.

Rahman, A. A., Mohd Sidek, N. Z., \& Tafri, F. H. (2009). Macroeconomic determinants of Malaysian stock market. African Journal of Business Management, 3 (3), 95-106.

Ross, S. A. (1976). The Arbitrage Theory of Capital Asset Pricing. Journal of Economic Theory, 13 (3), 341-360.

Sardar, M.N. I., Watanapalachaikul, S., \& Billington, N. (2004). A Time Series Analysis and Modelling of Thai Stock Market. Paper presented at UNITEN International Business Management Conference. Selangor: Universiti Tenaga Nasional. Retrieved from http://dspace.uniten.edu.my/jspui/ bitstream/123456789/624/1/A

Seehalak, T. (2004). SET Index Co-movement with Nikkei and Dow Jones (Unpublished master's thesis). Asian University of Science and Technology, Chonburi, Thailand.

Toda, H. Y., \& Yamamoto, T. (1995). Statistical inference in Vector Autoregressions with Possible Integrated Processes. Journal of Econometrics, 66 (1-2), 225-250.

Tri, E. (2005). Causality Testing on SET Index and Gross Domestic Product (GDP) (Unpublished master's thesis). Chiang Mai University, Chiang Mai, Thailand.

Zhao, X. Q. (1999). Stock prices, Inflation and Output: Evidence From China. Applied Economic Letters, 6 (8), 509-511. 